\title{
ESTUDO ANATÔMICO DO LENHO DE COLUBRINA GLANDULOSA PERKINS ${ }^{1}$
}

\author{
ANELISE MARTA SIEGLOCH ${ }^{2}$ SIDINEI RODRIGUES DOS SANTOS ${ }^{3}$ \\ JOSÉ NEWTON CARDOSO MARCHIORI ${ }^{4}$
}

\section{RESUMO}

É estudada a anatomia da madeira de Colubrina glandulosa Perkins, com base em material coletado em Santa Catarina. As características anatômicas observadas concordam com o referido na literatura para o gênero Colubrina Brongn., com exceção do parênquima paratraqueal escasso e da ausência de espessamentos espiralados em vasos. Além destes aspectos, salienta-se, na identificação da espécie, a presença de drusas no tecido radial. São também estabelecidas algumas observações sobre características tecnológicas da madeira. Palavras-chave: Anatomia da madeira, Colubrina glandulosa, Rhamnaceae.

\section{ABSTRACT}

[Wood anatomy of Colubrina glandulosa Perkins (Rhamnaceae)].

This paper deals with the wood anatomical study of Colubrina glandulosa Perkins, based on material from Santa Catarina state, Brazil. The main anatomical features are in accordance with literature references to genus Colubrina, except by the presence of scanty paratracheal parenchyma and the absence of spiral thickenings on vessel walls. Beside these aspects, the incidence of druses in ray cells is another important feature to the species identification. Some relations with technological aspects were also established.

Key words: Wood anatomy, Colubrina glandulosa, Rhamnaceae.

\section{INTRODUÇÃO}

A família Rhamnaceae notabiliza-se por apresentar espécies de morfologia e hábito muito variáveis, incluindo desde árvores e arbustos, frequentemente áfilos e recobertos de espinhos, até trepadeiras lenhosas e, mais raramente, ervas. De fato, são notáveis as adaptações apresentadas por alguns de seus representantes, como, por exemplo, Colletia paradoxa, um arbusto xerófilo de ramos fotossintetizantes, late-

1 Recebido para publicação em 14/06/2011 e aceito para publicação em 30/06/2011.

2 Acadêmica do Curso de Engenharia Florestal, bolsista de Iniciação Científica (PIBIC - CNPq), Universidade Federal de Santa Maria. Santa Maria, RS, Brasil. anesiegloch@yahoo.com.br

3 Biólogo, bolsista (CNPq - Brasil), doutorando do Programa de Pós-Graduação em Engenharia Florestal, Departamento de Ciências Florestais, Universidade Federal de Santa Maria, CEP 97105-900, Santa Maria, RS, Brasil. sthurt.bio@gmail.com

${ }^{4}$ Engenheiro Florestal, Dr. Bolsista de Produtividade em Pesquisa ( $\mathrm{CNPq}$ - Brasil). Professor Titular do Departamento de Ciências Florestais, Universidade Federal de Santa Maria. Santa Maria, RS, Brasil. ralmente comprimidos e transformados em espinhos triangulares, dispostos em cruz (Santos, 2008).

O Brasil conta com apenas 13 gêneros e 50 espécies nativas de Rhamnaceae (Sousa \& Lorenzi, 2005), sendo o Rio Grande do Sul o Estado mais bem representado, com 8 gêneros e 9 espécies (Bastos, 1988). A maioria dos representantes brasileiros da família são de pequeno porte, motivo pelo qual as espécies nativas resultam pouco interessantes sob o ponto de vista da utilização da madeira, embora úteis para outras finalidades (Souza \& Lorenzi, 2005). Destacam-se, pelo maior desenvolvimento do tronco: Colubrina glandulosa, Rhamnidium elaeocarpum e Scutia buxifolia.

Colubrina glandulosa - a única das três ainda carente de estudo anatômico detalhado -, produz madeira de boa qualidade, semelhante à do pau-brasil; por ser dura, pesada e extremamente resistente à deterioração, é indicada para construção naval, pontes, mourões, estacas, postes, dormentes, obras externas e veículos (Rizzini, 
1978). Fornece, igualmente, ótimos taboados, vigamentos e caibros, recomendando-se a espécie também para reflorestamentos (Johnston \& Soares, 1972) e recuperação de matas ciliares (Backes \& Irgang, 2009).

Trata-se de arvoreta ou árvore elegante, de até $25 \mathrm{~m}$ de altura e $80 \mathrm{~cm}$ de D.A.P., com tronco cilíndrico, reto e casca rugosa, longitudinalmente fissurada. A copa, muito característica, apresenta ramos finos e quase horizontais, que dão suporte a folhas oblongas $(6-16 \times 2-8,5 \mathrm{~cm})$, verde-escuras, brilhantes na face superior (Carvalho, 2005). Para o reconhecimento da espécie, salienta-se, ainda, a presença de glândulas arredondadas e enegrecidas nas folhas, bem como o denso indumento de tricomas ferrugíneos em ramos jovens, pecíolos e inflorescências (Bastos, 1990).

Conhecida, vulgarmente, por sobragi, saguari, sobrasil, falso-pau-brasil, sabiá-da-mata ou sucurujuva, entre outros nomes, Colubrina glandulosa distribui-se do Ceará ao Rio Grande do Sul (Carvalho, 2005). Ao lado de Rhamnidium elaeocarpum, já citada, é uma das espécies da família mais comuns na Floresta Estacional (Souza \& Lorenzi, 2005). No Rio Grande do Sul, habita tanto na Floresta Atlântica, como na Floresta Estacional da Serra Geral (Sobral et al., 2006), participando, sobretudo, na composição de matas secundárias e capoeiras, onde chega a formar pequenos agrupamentos (Reitz et al., 1988).

O presente estudo visa à descrição e análise da estrutura anatômica da madeira de Colubrina glandulosa, com vistas à valorização desta importante essência florestal.

\section{REVISÃO DE LITERATURA}

Apesar de sua importância, não constam na literatura referências anatômicas pormenorizadas sobre a espécie em estudo. Mainieri (1983) fornece uma breve caracterização dos aspectos macroscópicos da madeira, listando, entre ou- tras características: anéis de crescimento indistintos; poros pequenos, pouco numerosos, solitários e em múltiplos; parênquima indistinto, por vezes vasicêntrico-escasso; e máculas medulares freqüentes.

Para o gênero Colubrina, Record (1939) relaciona: anéis de crescimento distintos; poros escassos, pequenos a médios, solitários e em curtos múltiplos radiais e racemiformes; elementos vasculares com placas de perfuração simples e espessamentos espiralados; pontoações intervasculares pequenas a médias; raios heterogêneos, com 1-3 (até 4) células de largura e até 50 células de altura; pontoações raiovasculares pequenas a médias, arredondadas; parênquima vasicêntrico escasso até curtoaliforme e mais ou menos confluente; fibras com pontoações simples, paredes médias a espessas e comumente gelatinosas; e presença de séries cristalíferas em raios e no parênquima axial.

Marchiori (1983) e Santos et al. (2007a,b; 2008a,b) investigaram a anatomia de alguns representantes sul-rio-grandenses de outros gêneros da família: Colletia paradoxa, Discaria americana, Gouania ulmifolia, Rhamnus sphaerosperma e Scutia buxifolia. Com base nestes estudos, foram posteriormente estabelecidas tendências estruturais para as Ramnáceas sul-riograndenses (Santos \& Marchiori, 2009). De acordo com os resultados, são comuns para a família: poros numerosos, não exclusivamente solitários; elementos vasculares curtos, dotados de apêndices; placas de perfuração simples; pontoações intervasculares alternas, não ornamentadas; parênquima paratraqueal escasso, em séries não estratificadas; raios heterogêneos tipo II, não estratificados e não exclusivamente unisseriados; e fibras libriformes não septadas.

Outras referências anatômicas sobre Rhamnaceae podem ser encontradas nos trabalhos de Molle (1939), Record \& Hess (1949), Metcalfe \& Chalk (1972), Schirarend (1991), Mattos et al. (2003), Paula \& Alves (2007) e Marchiori et al. (2010). 


\section{MATERIAL E MÉTODOS}

O material em estudo consiste de uma amostra de madeira e respectivo material botânico, coletados no Campus da Universidade Federal de Santa Catarina, para os quais constam os seguintes registros: J.N.C. Marchiori, n. 162, Florianópolis, Santa Catarina.

Para a confecção das lâminas histológicas foram extraídos três corpos de prova $(1 \times 2 \times 3 \mathrm{~cm})$ da parte mais externa do lenho, próxima ao câmbio, orientados para obtenção de cortes nos planos transversal, longitudinal radial e longitudinal tangencial. Outro bloquinho foi também retirado, com vistas à maceração.

A confecção de lâminas histológicas seguiu a metodologia descrita em Burger \& Richter (1991). As lâminas de macerado foram obtidas de acordo com o método de Jeffrey (Freund, 1970). Os cortes anatômicos foram tingidos com acridina-vermelha, crisoidina e azul-de-astra (Dujardin, 1964); o macerado, apenas com safranina (1\%). A montagem das lâminas permanentes foi feita com Entellan.

A descrição baseou-se nas recomendações do IAWA Committee (Wheeler et al., 1989). No caso da percentagem dos tecidos, foram realizadas 600 determinações ao acaso, com auxílio de contador de laboratório, conforme proposto por Marchiori (1980). A freqüência de poros foi obtida a partir de um quadrado de área conhecida, superposto a fotomicrografias de seções transversais da madeira.

As medições foram realizadas em microscópio Carl Zeiss, no Laboratório de Anatomia da Madeira da Universidade Federal de Santa Maria. Nas características quantitativas, os números entre parênteses equivalem aos valores mínimos e máximos observados; o valor que acompanha a média é o desvio padrão. As fotomicrografias foram tomadas em microscópio Olympus CX40, equipado com câmera digital Olympus Camedia c3000, no Laboratório de Anatomia da Madeira da Universidade Federal do Paraná, a quem os autores agradecem.

\section{DESCRIÇÃO ANATÔMICA}

Madeira de porosidade difusa. Anéis de crescimento pouco distintos, marcados por estreita camada de fibras radialmente comprimidas no lenho tardio (Figura 1A,B).

Vasos: numerosos $(23 \pm 3,4(20-28)$ poros/ $\mathrm{mm}^{2}$ ), ocupando $15 \pm 0,75 \%$ do volume da madeira. Poros solitários e em curtos múltiplos radiais de 2-4 (7) poros, raro racemiformes, de seção circular, pequenos $(56 \pm 19(20-95) \mu \mathrm{m})$ e com paredes espessas $(4,5 \pm 0,9(2,5-6,2)$ $\mu \mathrm{m}$ ) (Figura 1A,B). Elementos vasculares de comprimento médio $(391 \pm 84,1(250-550)$ $\mu \mathrm{m})$, com placas de perfuração simples, ligeiramente oblíquas, e apêndices em uma ou ambas as extremidades. Pontoações intervasculares médias $(8,1 \pm 0,4(7,2-8,7) \mu \mathrm{m})$, alternas, circulares até ligeiramente poligonais, com abertura em fenda curta, inclusa, não ornamentada (Figura 1F). Pontoações raio-vasculares com aréolas distintas, semelhantes às intervasculares, embora menores $(5,9 \pm 0,9(5,1-7,2) \mu \mathrm{m})$ e, por vezes, unilateralmente compostas. Espessamentos espiralados e conteúdos, ausentes. $\mathrm{Na}$ parede de alguns vasos se observam estriações transversais que parecem originar-se na abertura das pontoações.

Parênquima axial: representando $10 \pm 2,1 \%$ do volume da madeira; em arranjo paratraqueal escasso (Figura 1A,B). Séries parenquimáticas de $246 \pm 81,3(107,5$ - 500) $\mu \mathrm{m}$ de altura, compostas de $2-4$ (5) células (Figura 1F).

Raios: muito numerosos $(14 \pm 2,2(11-17)$ raios/mm), com 1 - 3 células de largura, ocupando $19 \pm 1,6 \%$ do volume da madeira (Figura 1E,F). Raios multisseriados de $430 \pm 113$ (240 - 680) $\mu \mathrm{m}$ e 8-14 (22) células de altura; heterocelulares, compõem-se, geralmente, de células procumbentes no corpo multisseriado central e $1-4$ (6) fileiras marginais de células eretas e quadradas (Figura $1 \mathrm{C}, \mathrm{E}, \mathrm{F}$ ). Os unisseriados, compostos por células exclusivamente eretas ou eretas e quadradas, medem 333 $\pm 101(200-630) \mu \mathrm{m}$ e $2-10$ células de altura. 

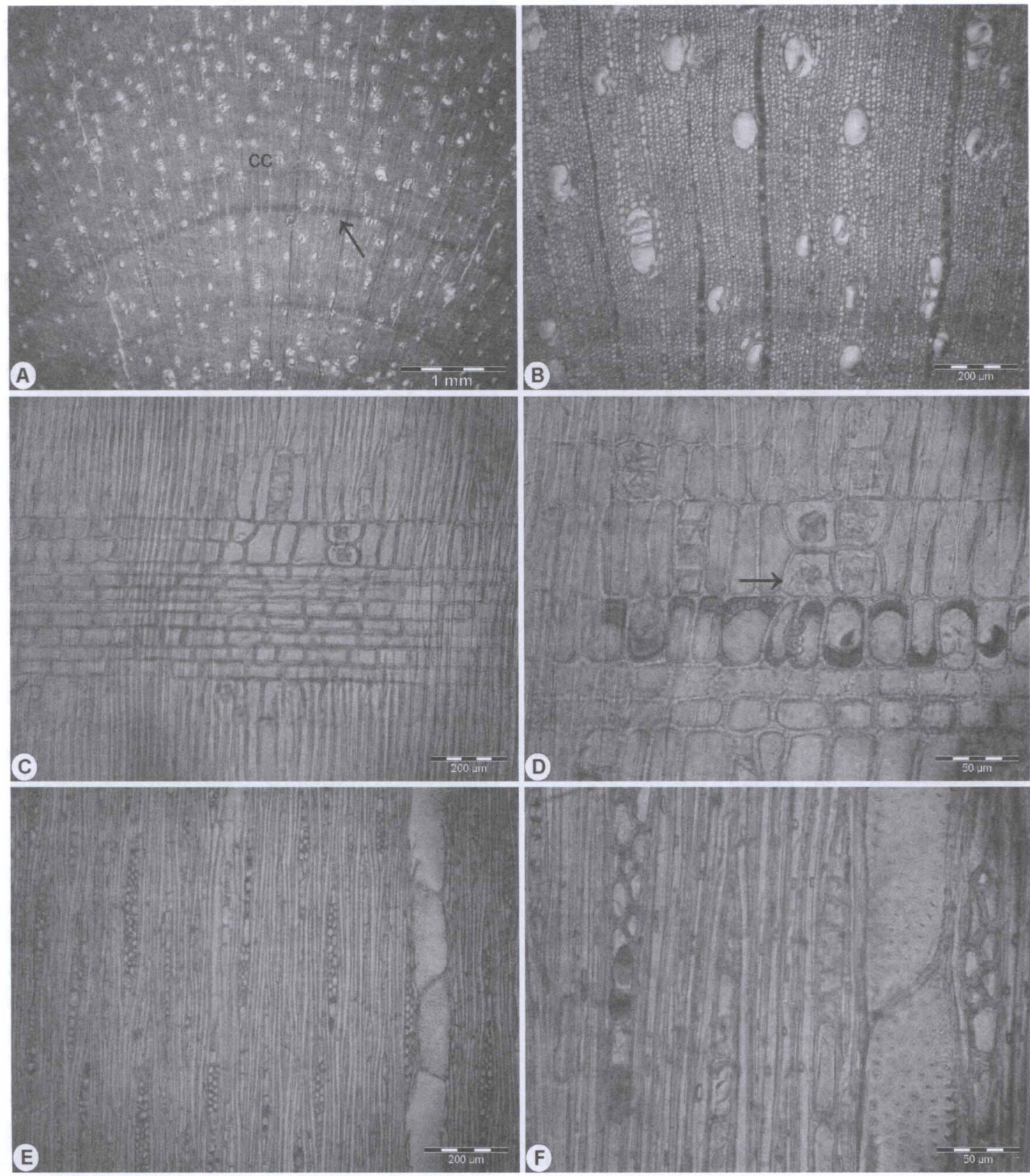

FIGURA 1 - Aspectos anatômicos da madeira de Colubrina glandulosa Perkins. A - Seção transversal, mostrando porosidade difusa, limite de anel de crescimento pouco distinto (cc) e fibras gelatinosas em faixas concêntricas (seta). B - Mesma seção, em maior aumento, com poros solitários e em múltiplos radiais, parênquima paratraqueal escasso e fibras de paredes finas a espessas. C - Raio heterogêneo, em seção longitudinal radial, com células procumbentes no corpo central, e células eretas e quadradas nas margens, com cristais. D - Seção longitudinal radial, em maior aumento, mostrando células marginais com cristais prismáticos, drusas (seta) e abundante conteúdo. E - Vista geral da seção longitudinal tangencial, com destaque para raios multisseriados com margens de até quatro células de altura. $\mathrm{F}$ - Detalhe de vasos com pontoações intervasculares alternas, circulares até ligeiramente poligonais, e raios uni e bisseriados (seção longitudinal tangencial). 
Células radiais de paredes disjuntas, presentes. Conteúdo, abundante em células marginais. Raios axialmente fusionados, freqüentes. Raios agregados, células envolventes e células perfuradas, ausentes.

Fibras: com pontoações inconspicuamente areoladas de diâmetro inferior a $3 \mu \mathrm{m}$, nas faces radiais da parede; fibras curtas $(848 \pm 123,6$ (560 - 1100) $\mu \mathrm{m})$, com 7,5 $\pm 1,8(5-12,5) \mu \mathrm{m}$ de largura, de paredes finas a espessas $4 \pm 1,2(2,5$ - 6,9) $\mu \mathrm{m}$ e seção frequentemente retangular, ocupando $56 \pm 2,3 \%$ do volume da madeira (Figura 1B). Fibras gelatinosas em faixas concêntricas que chegam, por vezes, a ocupar quase todo o anel de crescimento (Figura 1A,B). Fibras septadas, espessamentos espiralados e traqueídeos, ausentes.

Demais caracteres: variantes cambiais, tubos laticíferos e taníferos, canais intercelulares, células oleíferas, células mucilaginosas e estratificação, ausentes. Máculas medulares, presentes. Inclusões minerais abundantes, na forma de cristais prismáticos e drusas, dispostos em células eretas e quadradas da margem de raios, por vezes subdivididas, menos comumente no parênquima axial (Figura 1D).

\section{ANÁLISE DA ESTRUTURA ANATÔMICA}

A maioria das características anatômicas observadas na madeira de Colubrina glandulosa corresponde ao referido na literatura para o gênero Colubrina e família Rhamnaceae (Record, 1939; Record \& Hess, 1949; Metcalfe \& Chalk, 1972; Santos \& Marchiori, 2009): poros solitários e em curtos múltiplos radiais; elementos vasculares de comprimento médio, com placas de perfurações simples e pontoações intervasculares alternas; parênquima paratraqueal seriado; raios heterogêneos, estreitos; fibras libriformes curtas, frequentemente gelatinosas; e presença de cristais.

Record (1939) e Metcalfe \& Chalk (1972) atribuem, para o gênero em questão, a ocorrência de espessamentos espiralados e parênquima vasicêntrico ou confluente. No material em estudo, todavia, o parênquima axial é do tipo paratraqueal escasso e não foram observados espessamentos espiralados em vasos. Metcalfe \& Chalk (1972) também relacionam, para Colubrina, raios multisseriados com margens de quatro ou mais células de altura, aspecto igualmente não observado neste trabalho (margens, geralmente de até 4 células).

Especialmente interessantes são as inclusões minerais (cristais prismáticos e drusas) observadas na madeira de Colubrina glandulosa. A ocorrência de cristais prismáticos não é novidade para o gênero (Record, 1939). Esta característica, aliás, é comum na estrutura anatômica (especialmente em raios) de muitas Rhamnaceae, inclusive em espécies do Rio Grande do Sul (Marchiori, 1983; Santos \& Marchiori; 2009). A presença de drusas, apesar de não ter sido mencionada por nenhum dos autores até o momento referidos, também não constitui novidade para o gênero. Aspecto pouco comum e, portanto, de grande valor taxonômico -, a ocorrência de drusas em Colubrina foi anteriormente registrada por Wheeler et al. (1989) e Carlquist (2001). Segundo este autor, apresentam drusas, além de Colubrina, os gêneros Ceanothus e Rhamnus. Cabe salientar, por fim, que nenhuma outra espécie nativa da família, incluindo Rhamnus sphaerosperma (Santos et al., 2007b), apresenta este caráter anatômico.

No tocante às características tecnológicas, a ocorrência de poros de pequeno diâmetro e de fibras com paredes moderadamente espessas confere, presumivelmente, uma boa resistência mecânica à madeira, devido à relação direta destes aspectos anatômicos com o peso específico. A escassez de tecidos parenquimáticos, sabidamente mais fracos, contribui, igualmente, para a maior resistência mecânica da madeira.

A uniformidade no diâmetro e distribuição de poros, bem como na espessura da parede de fibras, associada à ausência de pontos de fragilidade (ex. raios largos e parênquima em faixas), são indícios de propriedades físicas e mecânicas homogêneas. A abundância de tecido gelatinoso, por sua vez, atribui maior flexibilidade à madeira. 
Já a presença de escasso tecido parenquimático, de abundantes conteúdos orgânicos e de cristais, justifica, ao menos em parte, a boa durabilidade natural da madeira. Vale lembrar, no entanto, que os cristais, ao mesmo tempo que aumentam a durabilidade, dificultam a trabalhabilidade, devido ao desgaste que provocam nos equipamentos. O mesmo se pode dizer da presença de conteúdos orgânicos, aspecto que pode dificultar o processamento da madeira.

\section{REFERÊNCIAS BIBLIOGRÁFICAS}

BACKES, P.; IRGANG, B. Árvores do Sul: guia de identificação e interesse ecológico. Porto Alegre: Paisagem do Sul. 2009. p. 280-281.

BASTOS, N.R. Estudos preliminares da família Rhamnaceae R. Br. no RS. Pesquisas - Botânica, São Leopoldo, n. 39, p. 41-48, 1988.

BASTOS, N.R. A familia Rhamnaceae R. Br. no RS: gêneros Colubrina Rich. ex Brongn., Gouania Jacq. e Hovenia Thunb. Pesquisas - Botânica, São Leopoldo, n. 41, p. 99-122, 1990.

BURGER, L.M.; RICHTER, H.G. Anatomia da Madeira. São Paulo: Ed. Nobel, 1991. 154 p.

CARLQUIST, S. Comparative Wood Anatomy: systematic, ecological and evolutionary aspects of Dicotyledon wood. Berlin: Springer-Verlag, 2001. 446p.

CARVALHO, P.E.R. Sobrasil. EMBRAPA: Colombo (PR), 2005. 10 p. (Circular Técnica 106).

DUJARDIN, E.P. Eine neue Holz-Zellulosenfaerbung. Mikrokosmos, n. 53, p. 94, 1964.

FREUND, H. Handbuch der Mikroskopie in der Technik. Frankfurt: Umsham Verlag, 1970. 375 p.

JOHNSTON, M.C.; SOARES, M.A.F. Ramnáceas. In: REITZ, R. Flora Ilustrada Catarinense. Itajaí: Herbário Barbosa Rodrigues, 1972. 50 p.

MAINIERI, C. Manual de identificação das principais madeiras comerciais brasileiras. São Paulo: Instituto de Pesquisas Tecnológicas. 1983. $241 \mathrm{p}$.

MARCHIORI, J.N.C. Comprovação da viabilidade da utilização da secção longitudinal tangencial para a determinação histométrica dos elementos axiais do xilema secundário. In: Anais do IV Congresso Florestal Estadual, Nova Prata, RS, p. 180-184, 1980.
MARCHIORI, J.N.C. Anatomia da madeira de Colletia paradoxa (Spreng.) Escalante. Ciência e Natura, Santa Maria, v. 5, p. 161-170, 1983.

MARCHIORI, J.N.C.; MUÑIZ, G.I.B.; SANTOS, S.R. Madeiras do Rio Grande do Sul. 2. Descrição microscópica de 35 espécies nativas. Santa Maria: Anaterra, 2010.80 p.

MATTOS, P.P.; TEIXEIRA, L.L.; SEITZ, R.A.; SALIS, M.S.; BOTOSSO, C.P. Anatomia de madeiras do Pantanal Mato-Grossense. Características microscópicas. Colombo: EMBRAPA Florestas. Corumbá: EMBRAPA Pantanal, 2003, $182 \mathrm{p}$.

METCALFE, C.R.; CHALK, L. Anatomy of the Dicotyledons. Oxford: Clarendon Press, 1972. p. 404-413.

MOLLE, C.C. Estructura anatómica del leño de las Ramnáceas argentinas del género Condalia (Piquilines). Physis, n. 15, 1939.

PAULA, J.E.; ALVES, J.L.H. 897 madeiras nativas no Brasil. Anatomia, dendrologia, dendrometria, produção e uso. Porto Alegre: Cinco Continentes, $2007.438 \mathrm{p}$.

REITZ, R.; KLEIN, R.M.; REIS, A. Projeto Madeira do Rio Grande do Sul. Porto Alegre: Sudesul, 1988. 525p.

RECORD, S.J. American woods of the family Rhamnaceae. Tropical Woods, n. 58, p. 6-24, 1939.

RECORD, S.J.; HESS, R.W. Timbers of the New World. New Haven: Yale University Press, 1949. p. $436-443$.

RIZZINI, C.T. Árvores e madeiras úteis do Brasil: manual de dendrologia brasileira. São Paulo: Edgard Blücher Ltda., 1978. p. 197-198.

SANTOS, S.R. Estudo anatômico do lenho e descrição morfológica de cinco espécies sul-riograndenses da família Rhamnaceae. 2008. 120 p. Dissertação (Mestrado em Engenharia Florestal). Universidade Federal de Santa Maria, Santa Maria, 2008.

SANTOS, S.R.; MARCHIORI, J.N.C. Estudos anatômicos em Rhamnaceae. Considerações taxonômicas, ecológicas e evolutivas. Balduinia, n. 16, p. 13-23, 2009.

SANTOS, S.R.; MARCHIORI, J.N.C.; CANTODOROW, T.S. Identificação botânica e anatomia da madeira de Discaria americana Gillies et Hooker. Balduinia, Santa Maria, n. 10, p. 1120, 2007a. 
SANTOS, S.R.; MARCHIORI, J.N.C.; CANTODOROW, T.S.; DENARDI, L. Estudo anatômico do lenho e descrição botânica de Rhamnus sphaerosperma Swartz (Rhamnaceae). Balduinia, Santa Maria, n. 11, p. 16-26, 2007 b.

SANTOS, S.R.; MARCHIORI, J.N.C.; CANTODOROW, T.S. Estudo anatômico do lenho e descrição morfológica de Gouania ulmifolia Hooker et Arnott (Rhamnaceae). Balduinia, Santa Maria, n. 13, p. 15-26, 2008a.

SANTOS, S.R.; MARCHIORI, J.N.C.; CANTODOROW, T.S. Anatomia da madeira e descrição morfológica de Scutia buxifolia Reissek (Rhamnaceae). Balduinia, Santa Maria, n. 14, p. 19-28, 2008b.

SCHIRAREND, C. The systematic wood anatomy of the Rhamnaceae Juss. (Rhamnales)
- Tribe Zizipheae. IAWA Bulletin, v.12, n. 4, p. 359-388, 1991.

SOBRAL, M.; JARENKOW, A.; BRACK, P.; IRGANG, B.; LAROCCA, J.; RODRIGUES, R. S. Flora arbórea e arborescente do Rio Grande do Sul. São Carlos: RiMa: Novo Ambiente, 2006. p. 142-143.

SOUZA, V.C.; LORENZI, H. Botânica Sistemática: guia ilustrado para identificação das famílias de Angiospermas da flora brasileira, baseado em APG II. Nova Odessa: Instituto Plantarum, 2005. 640 p.

WHEELER, E.A.; BAAS, P.; GASSON, P.E. IAWA list of microscopic features for hardwood identification. IAWA Bulletin, v.10, n. 3, p. 218359, 1989. 